\title{
Withering Government Spending Multipliers
}

\author{
Matthew Canzoneri* $\quad$ Fabrice Collard ${ }^{\dagger} \quad$ Harris Dellas $^{\ddagger} \quad$ Behzad Diba $^{\S}$
}

November 17, 2009

\begin{abstract}
The empirical literature has documented a weakening of the consumption and output responses to an increase in government spending during the last thirty years. We show that a New-Keynesian model augmented by a signal extraction problem can account for this development of government spending multipliers. And we find that the evolution of monetary policy and greater globalization (increasing international trade and decreasing capital controls) are the most important factors in the account.
\end{abstract}

JEL class: E32, E62, F39

${ }^{*}$ Georgetown University, Department of Economics, Washington, DC 20057, Tel: 202-687-5911, email:canzonem@georgetown.edu, Homepage:http://www9.georgetown.edu/faculty/canzonem/canzoneri.htm

${ }^{\dagger}$ The University of Adelaide, School of Economics, Napier Building, Ground Floor, North Terrace, Adelaide SA 5005, Australia. Tel: (61-8) 8303-4928, email: fabrice.collard@gmail.com, Homepage:http://fabcol.free.fr

${ }^{\ddagger}$ Department of Economics, University of Bern, CEPR. Address: VWI, Schanzeneckstrasse 1, CH 3012 Bern, Switzerland. Tel: (41) 31-6313989, email: harris.dellas@vwi.unibe.ch, Homepage: http://staff.vwi.unibe.ch/dellas

${ }^{\S}$ Georgetown University, Department of Economics, Washington, DC 20057, Tel: 202-687-5682, email: dibab@georgetown.edu, Homepage: http://www9.georgetown.edu/faculty/dibab/ 


\section{Introduction}

The response of consumption to an unanticipated increase in government spending has weakened over the last thirty years in most OECD countries, and output multipliers have also fallen. Perotti (2004), Perotti and Monacelli (2006) and Ravn, Schmitt-Grohe and Uribe (2007), show that there was a structural break around 1980 in the U.S., the U.K., Germany, Canada, and Australia. Pre-1980, the response of consumption was positive, while post-1980 it is near zero. Similarly, pre-1980 output multipliers were positive, and, at least in the U.S., greater than one; post-1980, they are near zero. As far as we are aware, there has been no rigorous attempt to model the evolution of government spending multipliers and to identify the factors that were important in their withering. That is our objective in this paper.

More specifically, we build a NOEM model and study two calibrations of it: one to pre-1980 (Canadian) data and the other to post-1980 data. These two calibrations are able to explain the observed evolution of consumption responses and output multipliers. Our model suggests that the most important factor was the evolution of monetary policy, in which the stabilization of exchange rates gave way to a standard Taylor Rule 1 Globalization (in the form of increased openness, and to a lesser extent, the relaxation of capital controls) also played a role. Luck (in the form of a more stable government spending process) was not an important factor ${ }^{2}$

As is well known, it is difficult to build a (so called) New-Keynesian model in which households increase their consumption in response to an unanticipated increase in government spending. The old Keynesian notion was that disaggregated households increased their spending in response to the income generated by the increased spending of others; this sequential process led to what became know as the Keynesian multiplier. In modern DSGE models, assumptions about consumption risk sharing lead to a representative consumer, and this representative consumer sees the increase in government spending as a tax liability, or a decrease in permanent income; the representative consumer wants to work more and consume less. This response is counter factual, at least for the pre-1980 period, and indeed, we find that our model cannot explain the evolution of output multipliers unless something is added to get around this negative wealth effect.

\footnotetext{
${ }^{1}$ There is a well documented change in monetary policies that began around 1980 in most OECD countries. The demise of the Bretton Woods system occurred somewhat earlier. The Canada/US exchange rate appears to have gotten more volatile around 1977 (the standard deviation of quarterly percentage changes in the 1977-2008 sample is about three times larger than in the 1960-1976 sample). Since the literature on government spending multipliers puts the break at 1980, and the literature on monetary policy also puts the break at 1980, we have chosen that date for our break in our two calibrations of the model.

${ }^{2}$ Parallel to the moderation of the effects of fiscal policy, there has been a widely documented moderation in the severity of the business cycle. Whether the fiscal moderation has contributed significantly to the total moderation or not remains an open issue. Fiscal shocks are rather unimportant for business cycles in the NK model.
} 
The most popular way of getting around the negative wealth effect is to model rule of thumb households - households that, for one reason or another, simply consume their current disposable income. This idea may be reminiscent of earlier Keynesian notions, but in calibration exercises, a very large fraction of total consumption must be attributed to the rule of thumbers if this kind of modelling is to fit the data $3^{3}$

We have chosen a different approach ${ }^{4}$ It seems plausible to assume that households and firms have imperfect information about macroeconomic (and possibly microeconomic, or idiosyncratic) shocks. They see their incomes rising, following an unanticipated government spending shock, but they are not sure why. Their perceptions are confounded by the possibility of other shocks that would actually increase their permanent income. As will be seen, a rather small amount of noise in agents' observations is sufficient in our calibrations for household consumption (and investment) to respond positively to the fiscal shock ${ }^{5}$

And indeed, imperfect information provides the fulcrum in our model for a Mundell-Flemming effect that plays an important role in what follows. With imperfect information, a government spending shock increases consumption, and this increase in aggregate demand puts upward pressure on the relative price of home goods. In a fixed exchange rate regime, the central bank must conduct expansionary open market operations to keep the nominal exchange rate from appreciating. This policy slows the rise in the relative price of home goods and keeps it from curbing the increase in aggregate demand; government spending multipliers are large. In a flexible rate regime, the relative price of home goods rises faster, and the multipliers are diminished. This is a familiar story. But, the point here is that the Mundell-Flemming effect is never set in motion in a standard NOEM without imperfect information: consumption must rise following the increase in government spending if the flexibility of the exchange rate is to matter for output multipliers.

A related observation is that a perfectly observed (or fully anticipated) increase in government spending will not increase consumption in our model, and this fact may be consistent with a different branch of the literature on government spending multipliers. The event study approach used by Ramey and Shapiro (1998) and others typically finds that easily identified episodes of large increases in defense spending cause output to increase, but private consumption to fall. Once again, imperfect information is required in our model if consumption is to rise in response

\footnotetext{
${ }^{3}$ See for example Galì, López-Salido and Vallés (2007), Coenen and Straub (2005), or Erceg, Guerrieri and Gust (2005).

${ }^{4}$ Recently, Perotti and Monacelli (2006), Ravn, Schmitt-Grohe and Uribe (2007) have suggested other explanations: non-separable utility and deep habits. It is too early to tell whether these alternative explanations will gain traction.

${ }^{5}$ Using the Real Time Data Set of the Philadelphia FED for the US we establish that the measurement error in real government expenditure in the US is quite substantial. And that the amount of misperception in real public spending required by the model is considerably smaller than that present in real time releases of US public spending data.
} 
to an increase in government spending.

The rest of the paper proceeds as follows. In section 2, we outline our model and our calibration of a pre-1980 benchmark and a post-1980 benchmark. In section 3, we show that the two benchmarks are able to explain the evolution of government spending multipliers (and the weakening of consumption responses) that has been observed in the data. Since the change in monetary policy plays an important role in the model's explanation of this evolution, we also calculate the multipliers under some other monetary policies - a fixed money growth rule and a strict inflation targeting rule. The money growth rule was the alternative to a fixed exchange rate regime in the Mundell-Flemming paradigm, and a strict inflation targeting rule may be the direction in which many central banks in the OECD are headed. Section 4 concludes with some caveats and directions for future research.

\section{The Model}

The model consists of a small domestic economy and a large foreign economy (or rest of the world). The domestic economy is characterized by monopolistic competition and Calvo price setting, competitive labor markets and flexible wage rates, endogenous capital accumulation, and imperfect information about macroeconomic shocks. The household's signal extraction problem causes its consumption to rise in response to an unanticipated increase in government spending.

\subsection{Production of the domestic final good}

The domestic final good, $y$, can be used for domestic consumption (private and public) or for investment. Competitive firms produce this final good by combining domestic $\left(x_{d}\right)$ and foreign $\left(x_{f}\right)$ goods. A CES aggregator describes their production function

$$
y_{t}=\left(\omega^{1-\rho} x_{d, t}^{\rho}+(1-\omega)^{1-\rho} x_{f, t}^{\rho}\right)^{\frac{1}{\rho}}
$$

where $\omega \in(0,1)$ and $\rho \in(-\infty, 1)$.

Cost minimization by the final good producers implies the demand functions

$$
\begin{aligned}
& x_{d, t}=\left(\frac{P_{x t}}{P_{t}}\right)^{\frac{1}{\rho-1}} \omega y_{t} \\
& x_{f, t}=\left(\frac{e_{t} P_{x t}^{\star}}{P_{t}}\right)^{\frac{1}{\rho-1}}(1-\omega) y_{t}
\end{aligned}
$$

where $P_{x t}$ and $e_{t} P_{x t}^{\star}$ denote the home currency price of the domestic and the foreign goods. The 
final good's price is

$$
P_{t}=\left(\omega P_{x t}^{\frac{\rho}{\rho-1}}+(1-\omega)\left(e_{t} P_{x t}^{\star}\right)^{\frac{\rho}{\rho-1}}\right)^{\frac{\rho-1}{\rho}}
$$

Competitive firms produce $x_{t}=x_{d, t}+x_{d, t}^{\star}$ (and $x_{t}^{\star}$ abroad) by combining domestic and foreign intermediate goods

$$
x_{t}=\left(\int_{0}^{1} x_{d, t}(i)^{\theta} \mathrm{d} i\right)^{\frac{1}{\theta}}
$$

where $\theta \in(-\infty, 1)$. And again, cost minimization give the demand for intermediate goods

$$
x_{d, t}(i)=\left(\frac{P_{x t}(i)}{P_{x t}}\right)^{\frac{1}{\theta-1}} x_{d, t}
$$

Likewise, the domestic demand for the foreign intermediate good $i$ is given by

$$
x_{f, t}(i)=\left(\frac{P_{x t}^{\star}(i)}{P_{x t}^{\star}}\right)^{\frac{1}{\theta-1}} x_{f, t}
$$

where

$$
P_{x t}=\left(\int_{0}^{1} P_{x t}(i)^{\frac{\theta}{\theta-1}} \mathrm{~d} i\right)^{\frac{\theta-1}{\theta}}, P_{x t}^{\star}=\left(\int_{0}^{1} P_{x t}^{\star}(i)^{\frac{\theta}{\theta-1}} \mathrm{~d} i\right)^{\frac{\theta-1}{\theta}}
$$

\subsection{Production of the domestic intermediate goods}

Each intermediate firm $i, i \in(0,1)$, uses a constant returns to scale technology

$$
x_{t}(i) \leqslant A_{t}\left(u_{t} k_{t}(i)\right)^{\alpha} h_{t}(i)^{1-\alpha}-\mathscr{F} \text { with } \alpha \in(0,1)
$$

where $k_{t}(i)$ and $h_{t}(i)$ denote capital and labor. $A_{t}$ is an exogenous technology shock whose properties will be defined later. $\mathscr{F}>0$ is a fixed cost. Households supply capital and labor competitively; the wage and rental rates, $w_{t}$ and $r_{k, t}$, are flexible. Households also set the capital utilization rate, $u_{t}$. The firm determines its production plan by minimizing its real cost

$$
\min _{\left\{u_{t} k_{t}(i), h_{t}(i)\right\}} w_{t} h_{t}(i)+r_{k, t} u_{t} k_{t}(i)
$$

subject to (9). Minimized real total costs are then given by $\psi_{t} x_{t}(i)$ where the real marginal cost, $\psi_{t}$, is given by

$$
\frac{r_{k, t}^{\alpha} w_{t}^{1-\alpha}}{\varsigma A_{t}}
$$

with $\varsigma=\alpha^{\alpha}(1-\alpha)^{1-\alpha}$.

Intermediate goods producers are monopolistically competitive, and therefore set prices for the good they produce. Following Calvo (1983), in any given period, a firm gets to adjust its price 
optimally with probability $\gamma$. If the firm does not get this chance, then its price is automatically indexed to the steady state rate of inflation, $\bar{\pi}$

$$
P_{x t}(i)=\bar{\pi} P_{x t-1}(i)
$$

A firm that does get to adjust will set its price at

$$
\tilde{P}_{x t}(i)=\frac{1}{\theta} \frac{\mathbb{E}_{t} \sum_{\tau=0}^{\infty}(1-\gamma)^{\tau} \Phi_{t+\tau} P_{t+\tau}^{\frac{2-\theta}{1-\theta}}\left(\bar{\pi}^{\tau}\right)^{\frac{1}{\theta-1}} \psi_{t+\tau} y_{t+\tau}}{\mathbb{E}_{t} \sum_{\tau=0}^{\infty}(1-\gamma)^{\tau} \Phi_{t+\tau}\left(\bar{\pi}^{\tau}\right)^{\frac{\theta}{\theta-1}} P_{t+\tau}^{\frac{1}{\theta-1}} y_{t+\tau}}
$$

where $\Phi_{t+\tau}$ is an appropriate discount factor derived from the household's optimality conditions. Since the price setting scheme is independent of any firm specific characteristic, all firms that reset their prices will choose the same price.

In each period, a fraction $\gamma$ of price contracts ends and a fraction $(1-\gamma)$ survives. Hence, from (4) and the price mechanism, the aggregate price of the domestic good becomes

$$
P_{x t}=\left(\gamma \widetilde{P}_{x t}(i)^{\frac{\theta}{\theta-1}}+(1-\gamma)\left(\bar{\pi} P_{x t-1}\right)^{\frac{\theta}{\theta-1}}\right)^{\frac{\theta-1}{\theta}}
$$

\subsection{The household}

Household utility is

$$
\mathbb{E}_{t} \sum_{\tau=0}^{\infty} \beta^{\tau} \log \left(c_{t+\tau}-b c_{t+\tau-1}\right)+\frac{\nu^{m}}{1-\sigma_{m}}\left(\frac{M_{t+\tau}}{P_{t+\tau}}\right)^{1-\sigma_{m}}-\frac{\nu^{h}}{1+\sigma_{h}} h_{t+\tau}^{1+\sigma_{h}}
$$

where $c_{t}$ denotes consumption of the final good, $M_{t} / P_{t}$ is (end of period) real money balances held by the household, and $h_{t}$ is hours worked by the household; $0<\beta<1$ is a constant discount factor, and $b$ is a parameter that measures the degree of habit persistence in consumption.

The household's budget constraint is

$$
\begin{aligned}
B_{t}^{\mathrm{D}}+e_{t} B_{t}^{\mathrm{F}}+M_{t}+P_{t}\left(c_{t}+i_{t}+z\left(u_{t}\right) k_{t}+\tau_{t}\right)= & R_{t-1} B_{t-1}^{\mathrm{D}}+R_{t-1}^{\star} e_{t} B_{t-1}^{\mathrm{F}}-\frac{\chi}{2} P_{t}\left(\frac{e_{t} B_{t}^{\mathrm{F}}}{P_{t}}\right)^{2} \\
& +P_{t} r_{k, t} u_{t} k_{t}+P_{t} w_{t} h_{t}+M_{t-1}+\Pi_{t}
\end{aligned}
$$

where $B_{t}^{\mathrm{D}}$ and $B_{t}^{\mathrm{F}}$ are domestic and foreign currency bonds, and $\tau_{t}$ is a lump sum tax used by the government to balance its budget each period. The foreigners do not hold domestic bonds; so, $B_{t}^{\mathrm{D}}=0$ in equilibrium $\sqrt[6]{\frac{\gamma}{2}} P_{t}\left(\frac{e_{t} B_{t}^{\mathrm{F}}}{P_{t}}\right)^{2}$ is an adjustment cost on foreign bond holdings. $i_{t}$ is household investment, and $k_{t}$ is the amount of physical capital owned by the household and

\footnotetext{
${ }^{6}$ There is no need to model government bonds since the government is assumed to balance the fiscal budget period by period.
} 
leased to the firms; $u_{t}$ is the household's choice of the capital utilization rate. Utilization of the capital triggers a utilization cost of $z\left(u_{t}\right) k_{t}$, where $z(\cdot)$ is a convex strictly increasing function, with $z(\bar{u})=0$ and $z^{\prime \prime}(\bar{u}) \bar{u} / z^{\prime}(\bar{u})=\sigma_{z}$. Households own the domestic firms, and $\Pi_{t}$ are their profits. Finally, $\chi>0$ measures the strength of capital controls on the household's holdings of foreign assets.

Capital accumulates according to the law of motion

$$
k_{t+1}=i_{t}-\frac{\varphi}{2}\left(\frac{i_{t}}{k_{t}}-\delta\right)^{2} k_{t}+(1-\delta) k_{t}
$$

where $\delta \in[0,1]$ denotes the rate of depreciation. Capital accumulation is subject to increasing and convex capital adjustment costs.

The household then maximizes (13) subject to (14)-15. Its first order conditions are given in an appendix.

\subsection{Monetary policy}

We will generally characterize monetary policy by an interest rate rule of the form

$$
R_{t}=\rho_{r} R_{t-1}+\left(1-\rho_{r}\right)\left[\gamma_{\pi} \pi_{t}+\gamma_{y} y_{t}+\gamma_{\Delta e} \Delta e_{t}\right]
$$

where $\Delta e_{t}$ is the rate of depreciation. However, we will also consider the case where the central bank follows a constant money growth rule, $M_{t}=\left(1+g_{m}\right) M_{t-1}$.

\subsection{The rest of the world}

We model the foreign economy with an analogous, but stripped down, structure. Foreign demand for the domestic good is

$$
x_{d, t}^{\star}=\left(\frac{P_{x t}}{e_{t} P_{t}^{\star}}\right)^{\frac{1}{\rho-1}}\left(1-\omega^{\star} \exp \left(-\zeta_{\omega t}\right)\right) y_{t}^{\star}
$$

where $\zeta_{\omega t}$ is a preference shock. We do not model investment in the foreign economy; so $c_{t}^{\star}=$ $y_{t}^{\star}$. Both $y_{t}^{\star}$ and $\pi_{t}^{\star}$ are modelled as exogenous AR(1) processes. Finally, an Euler equation determines the foreign interest rate, $R_{t}^{\star}$.

$$
\frac{1}{y_{t}^{\star}}=\beta R_{t}^{\star} \mathbb{E}_{t}\left[\frac{1}{y_{t+1}^{\star} \pi_{t+1}^{\star}}\right]
$$




\subsection{Imperfect information and the signal extraction problem}

Uncertainty (misperceptions) about the true level of real government spending plays a crucial role in our analysis. It enables the model to: generate a positive response of consumption to a positive spending shock; and also to capture the size and evolution of multipliers during the last few decades. Before proceeding any further we need to convince the readers that, while information on real government spending is available with a short time lag (one or two quarters), it is ridden with substantial measurement error. To this purpose, and lacking suitable data for Canada, we will use the real time data set of the Philadelphia FED 7 to compute the measurement error in reported real US government spending. Given the nature of data collection and processing in the industrial countries, we speculate that the properties of measurement error in real public spending in Canada and the US are likely to be quite similar.

Let $G_{t \mid t}$ be the initial release of government spending of period t (first reported in vintage t +1 ) and $g_{t \mid t}=\log G_{t \mid t}-\log G_{t-1 \mid t}$ its growth rate. Let $G_{t \mid t+i}\left(\right.$ resp. $\left.g_{t \mid t+i}=\log G_{t \mid t+i}-\log G_{t-1 \mid t+i}\right)$ be the revised figure for period that is available in period $t+i, i>1$. We use $t+i=T$ to represent the "final" release. The measurement error in real government spending growth in period $\mathrm{t}$ is then $\mu_{t \mid T}=g_{t \mid T}-g_{t \mid t}$.

Table 1 reports the properties (standard deviation and autocorrelation) of the measurement error in the growth of real spending 8 . As can be see these errors are quite substantia $1^{9}$ and do

Table 1: Properties of Measurement Error in US Real Government Expenditures

\begin{tabular}{cccc}
\hline \hline & Std. Dev. & Autocorr. & \\
\cline { 1 - 2 } 1966Q1-2002Q4 & 1.15 & 0.03 & Note: Standard deviations (in percent, quarterly \\
1966Q1-1980Q4 & 1.13 & 0.17 & rates) in parenthesis. \\
1981Q1-2002Q4 & 1.11 & -0.16 &
\end{tabular}

not display serial correlation.

The concept of unperceived government spending shocks play a key role in the analysis. But do these measurement errors capture misperceptions? The answer would be affirmative if they could not be predicted on the basis of information that was available at the time of the initial release. The approach of Mankiw et al., 1984, can be used to test for the presence or absence of predictability in these errors. In Table 2 , we report the results from a regression of $\mu_{t \mid T}$ on ${ }^{10}$

\footnotetext{
${ }^{7}$ The data can be downloaded from http://www .phil.frb.org/research-and-data/real-time-center/real-time-data/.

${ }^{8} \mathrm{We}$ end the sample in 2002 in order to leave room for the computation of subsequent revisions.

${ }^{9}$ Relative to both the volatility of the various shocks and the volatility of measurement error in other macroeconomic variables. For the latter see Collard and Dellas, 2007.

${ }^{10}$ Note that Table 1 already indicates the absence of autocorrelation and hence of predictability based on own lagged values in $\mu_{t \mid T}$. But this is not sufficient to establish the lack of predictability as there may be other variables at the time of the release that could help forecast future government spending.
} 
values of the federal fund rate $(R)$ and changes in the stock market ${ }^{11}(\Delta S P)$, as in Mankiw et al., 1984.

Table 2: Forecasting regressions

\begin{tabular}{ccccc}
\hline \hline \multicolumn{1}{c}{ Cst. } & $R_{t}$ & $\Delta S \& P$ & D.W. & $R^{2}$ \\
\hline $\begin{array}{c}1966 Q 1-2002 Q 4 \\
-0.0033\end{array}$ & 0.1683 & 0.0087 & 1.95 & 0.01 \\
$(0.0023)$ & $(0.1241)$ & $(0.0122)$ & & \\
-0.0030 & 0.1539 & - & 1.95 & 0.01 \\
$(0.0023)$ & $(0.1223)$ & & & \\
-0.0004 & - & 0.0060 & 1.93 & 0.00 \\
$(0.0009)$ & & $(0.0121)$ & & \\
\hline $1966 Q 1-1980 Q 4$ & & & \\
-0.0105 & 0.3722 & -0.0224 & 1.85 & 0.10 \\
$(0.0039)$ & $(0.2090)$ & $(0.0185)$ & & \\
-0.0115 & 0.4446 & - & 1.80 & 0.08 \\
$(0.0038)$ & $(0.2011)$ & & & \\
-0.0039 & - & -0.0318 & 1.75 & 0.05 \\
$(0.0015)$ & & $(0.0180)$ & & \\
\hline $1981 Q 1-2002 Q 4$ & & & \\
0.0006 & 0.0538 & 0.0262 & 2.34 & 0.03 \\
$(0.0027)$ & $(0.1458)$ & $(0.0156)$ & & \\
0.0012 & 0.0350 & - & 2.32 & 0.00 \\
$(0.0027)$ & $(0.1469)$ & & & \\
0.0015 & - & 0.0257 & 2.34 & 0.03 \\
$(0.0012)$ & & $(0.0155)$ & & \\
\hline \hline
\end{tabular}

Note: $R=$ Federal funds rate, $\Delta S \& P=$ changes in the $S \& P$ stock market index. Standard deviations (in percent, quarterly rates)in parenthesis.

As can be seen from the Table, measurement errors cannot be predicted so they can be taken as representing a legitimate measure of unperceived real government spending.

Having established that reported real government spending contains a significant misperceived component, we now turn to the discussion of the informational setup of the model. With the exception of financial prices variables, all aggregate variables tend to be observed with noise. For an imperfectly observed variable $x$ we assume that

$$
x_{t}=x_{t}^{\mathrm{T}}+\eta_{t}
$$

where $x_{t}^{\mathrm{T}}$ denotes the true value of the variable, $x_{t}$ is the value actually observed in period $\mathrm{t}$ and $\eta_{t}$ is a measurement error that satisfies $E\left(\eta_{t}\right)=0$ for all $t, E\left(\eta_{t} \varepsilon_{a, t}\right)=E\left(\eta_{t} \varepsilon_{g, t}\right)=E\left(\eta_{t} \varepsilon_{\mu, t}\right)=0$,

\footnotetext{
${ }^{11}$ Asset prices are the natural candidate as they are accurately measured and should also capture forecastable moves in future economic conditions. We have also considered additional variables whose values are available at the time of the release. The results remain the same.
} 
and

$$
E\left(\eta_{t} \eta_{k}\right)= \begin{cases}\sigma_{\eta}^{2} & \text { if } t=k \\ 0 & \text { Otherwise }\end{cases}
$$

Agents use the Kalman filter to update their beliefs about the state of the economy based on the history of observations $\left\{x_{t}, x_{t-1}, \ldots\right\}$ as well as their knowledge of the model. The solution is described in some detail in a technical appendix to Collard and Dellas (2007).

There exist many possibilities and a great deal of arbitrariness in specifying the details of the signal extraction problem. This is because the variables are linked through the equations of the model and the size of the system (and hence the number of variables) can be arbitrarily reduced through successive substitutions (see Svensson and Woodford, 2003). In general, there exist many different specifications of the information structure (the distribution of signals across variables) that lead to similar results. The structure we chose - while arbitrary - satisfies the following weak requirements: First, the signal extraction problem is meaningful. That is, the information available does not allow the agents to infer the true values of the variables. Second, financial prices, namely the nominal exchange rate and the nominal interest rate, are perfectly observed. Third, inflation and output are directly but imperfectly observed. This implies that the other aggregate variables are also imperfectly observed but indirectly (that is, through the solution of the model, which the agents can execute). And fourth, the amount of misperception implied by the model regarding the key variable, namely real government spending, does not exceed that implied by the measurement error in the US data. The last requirement guarantees that the results do not hinge on excessively large informational frictions.

We estimate a non-constrained version of equation $19-x_{t}=\alpha_{0}+\alpha_{1} x_{t}^{\mathrm{T}}+\eta_{t}-$ for GDP and inflation respectively in the US using the Philadelphia FED Real Time Data Set and test that the estimation results conform indeed to the specification used in this paper (namely, equation 19p. This test involves testing the joint restriction $\alpha_{0}=0$ and $\alpha_{1}=1$. The results indicate that the restriction cannot be rejected (first column of Table 3). We then use the standard error of these regressions (reported in the second column) as our measure of $\sigma_{\eta}^{2}$ for $y$ (and $y^{\star}$ ) and $\pi$ (and $\pi^{\star}$ ) respectively. As can be seen, both output and inflation are significantly afflicted

Table 3: Measurement Errors in US Inflation and Output

\begin{tabular}{ccc}
\hline \hline & Test & $\sigma_{\eta}(\%)$ \\
\hline Output & 0.1582 & 0.59 \\
& {$[0.8538]$} & \\
Inflation & 3.0185 & 0.22 \\
& {$[0.0519]$} & \\
\hline \hline
\end{tabular}

Note: p-values in brackets. Sample: 1966-2002. 
by measurement error. Again the hope is that these numbers do not differ much from their Canadian counterparts.

\subsection{Parametrization}

We parameterize our model using quarterly Canadian data for the period 1962Q1 to 2003Q4 12 We will have two benchmark calibrations: the Benchmark Fixed Rate (or Bfixed) calibration for the pre-1980 period and the Benchmark Flexible Rate (or Bflex) calibration for the post1980 period. This terminology is somewhat inappropriate, since the emphasis on exchange rate stabilization waned in the mid 1970s. However, the language highlights a prominent difference between the two periods, and one that will be important in what follows. The parameters for the two benchmark calibrations are reported in Table 44 where the other parameters differ in the two calibrations, the first number is for Bfixed and the second is for Bflex. In the Bfixed calibration, monetary policy fixes the nominal exchange rate; in the Bflex calibration, monetary policy is governed by an estimated Taylor rule.

We set the preference parameters at values that are commonly used in the Business Cycle literature. We set $\beta$, the discount factor, so that households discount the future at a $4 \%$ annual rate. We set $\sigma_{m}$, the inverse of the elasticity of money demand, at 1.5. We let $\sigma_{h}$, the inverse of the Frisch labor supply elasticity, be equal to 1 . We set $\nu^{h}$ so that households devotes $30 \%$ of their time to productive activities in the steady state. And finally, we set $b$, the habit persistence parameter, at 0.50 .

On the supply side, we set $\theta$ so that there is a $20 \%$ price markup (over marginal cost) in the steady state. We set $\alpha$, so that the labor share is 0.58 in the steady state. The national accounts report that the share of profits in GDP is very small. So, we set $\mathscr{F}$, the fixed cost of production, so that profits are zero in steady state. We take $\sigma_{m}$, the elasticity parameter in the capital utilization cost, from Christiano et al. (2005). We set the Calvo parameter so that firms reset their prices every 2.5 quarters on average.

We set $\rho$ so that the elasticity of substitution between the foreign and domestic good is equal to 1.5. We set $\omega$ so as to match the historical import shares during the two benchmark calibrations, $20 \%$ for the pre-1980 period, and 28\%. for the post-1980 period. We set the corresponding parameter for the world economy at 0.99 , implying that Canadian exports are $1 \%$ of the world economy's consumption. Based on Canadian and world GDP data, we assume that the world economy is about 30 times bigger than the Canadian economy. We follow Dib (2003) and set the parameter, $\chi$, equal to 0.005 in the pre-1980 period; in the post-1980 period, we assume that it has dropped to 0.0025 to account for the relaxation of capital controls.

\footnotetext{
${ }^{12}$ The data was taken from the OECD's main economic indicators.
} 
Table 4: Benchmark calibration

\begin{tabular}{|c|c|c|}
\hline$\overline{\text { Parameter }}$ & Mechanism & Value \\
\hline \multicolumn{3}{|c|}{ Preferences } \\
\hline$\beta$ & Discount factor & 0.9900 \\
\hline$\sigma_{m}$ & Money demand inverse elasticity & 1.5000 \\
\hline$\sigma_{h}$ & Inverse of labor supply elasticity & 1.0000 \\
\hline$b$ & Habit parameter & 0.5000 \\
\hline$h$ & Hours worked & 0.3000 \\
\hline \multicolumn{3}{|c|}{ Technology (intermediate good) } \\
\hline$\alpha$ & Capital elasticity & 0.4727 \\
\hline$\mu$ & Markup rate (goods) & 0.2000 \\
\hline$\theta$ & CES aggregate (goods) & 0.8333 \\
\hline $\mathscr{F}$ & Fixed cost & 0.5605 \\
\hline$\sigma_{z}$ & Elasticity of capital utilization cost & 0.0100 \\
\hline \multicolumn{3}{|c|}{ Technology (final good) } \\
\hline$\rho$ & Elasticity of substitution (home vs foreign) & $1 / 3$ \\
\hline$\omega$ & share of domestic goods (home) & $0.8000-0.7200$ \\
\hline$\omega^{\sigma}$ & share of world goods (world) & 0.9900 \\
\hline$y^{\star} / y$ & relative size of the world & 30.0000 \\
\hline$\chi$ & portfolio adjustment costs parameter & $0.0050-0.0025$ \\
\hline \multicolumn{3}{|c|}{ Capital Accumulation } \\
\hline$\delta$ & Depreciation rate & 0.0250 \\
\hline$\varphi_{k}$ & Capital adjustment cost parameter & 4.5000 \\
\hline \multicolumn{3}{|c|}{ Nominal rigidities } \\
\hline$\gamma$ & Price stickiness & 0.4000 \\
\hline \multicolumn{3}{|c|}{ Monetary Policy } \\
\hline$\rho$ & Interest rate smoothing & 0.6900 \\
\hline$\kappa_{\pi}$ & Weight on inflation & 1.3000 \\
\hline$\kappa_{y}$ & Weight on output & 0.0575 \\
\hline$\kappa_{\Delta} e$ & Weight on nominal exchange rate & $0.0350-\infty$ \\
\hline \multicolumn{3}{|c|}{ Shocks } \\
\hline$g / y$ & Share of governmemt expenditures & 0.186 \\
\hline$\rho_{a}$ & Technology shock (persistence) & 0.95 \\
\hline$\rho_{g}$ & Fiscal shock (persistence) & $0.96-0.78$ \\
\hline$\rho_{y}^{\star}$ & World output (persistence) & 0.92 \\
\hline$\rho_{\pi}^{\star}$ & World inflation (persistence) & 0.77 \\
\hline$\rho_{\zeta}^{\star}$ & Preference shock (persistence) & 0.96 \\
\hline$\sigma_{a}$ & Technology shock (volatility) & 1.03 \\
\hline$\sigma_{g}$ & Fiscal shock (volatility) & $2.09-1.54$ \\
\hline$\sigma_{y}^{\star}$ & World output (volatility) & 0.82 \\
\hline$\stackrel{y}{\sigma_{\pi}^{\star}}$ & World inflation (volatility) & 0.51 \\
\hline$\sigma_{\zeta}^{\star}$ & Preference shock (volatility) & 0.09 \\
\hline \multicolumn{3}{|c|}{ Noise } \\
\hline$\sigma_{\zeta}^{\pi}$ & Noise in inflation (volatility) & 0.2 \\
\hline$\sigma_{\zeta}^{\underline{y}}$ & Noise in output (volatility) & 0.6 \\
\hline
\end{tabular}


We set the parameters pertaining to capital accumulation at values that are standard in the Business Cycle literature. We set $\delta$, the quarterly depreciation rate, to make capital depreciate at a $10 \%$ annual rate. We set $\varphi_{k}$, the capital adjustment cost parameter, to roughly match the investment/capital ratio elasticity of the capital adjustment costs specification reported in Boldrin et al. (1999) for the US economy.

We characterize monetary and fiscal policy by estimated rules. We use Lubik and Schorfheide's (2007) estimate of the Canadian Taylor rule. The (log of) government spending follows an AR(1) process. Canadian data from the national accounts was linearly detrended, and then the process was estimated for the two sample periods.

We assume all shocks follow AR(1) processes. The technology shock was estimated using Solow residuals. In particular, we built a capital series by iterating on investment (obtained from the national accounts). Then, using the employment and output data, we calculated the Solow residual and estimated the $\mathrm{AR}(1)$ process for technology.

We assume that the rest of the world can be approximated by the U.S. The processes for world output and world inflation were estimated using U.S. data. The (log of ) output was linearly detrended. The preference shock was calibrated using U.S. demand for the Canadian good. As a consequence, $x_{d}^{\star}$, is identified as Canadian exports to the U.S. And, the U.S. - Canadian terms of trade appears in the world demand function for Canadian goods. Using the value for $\rho$ and $\omega^{\star}$, we built a series for the preference shock and estimated an $\operatorname{AR}(1)$ process for it.

Finally, the values of the measurement error in inflation and output are taken from the second column of Table 3 .

\section{The Evolution of Government Spending Multipliers}

We are now ready to examine whether our model can explain the evolution of government spending multipliers that has been observed in the data. It is instructive to begin with the special case of perfect information, then we will proceed to the more interesting case of imperfect information.

\subsection{The (counter factual) case of perfect information}

Here we assume that households and firms observe macroeconomic variables without error, and that there is therefore no signal extraction problem. Table 5 shows the cumulative output multipliers for an increase in government spending at horizons of 1, 4 and 8 quarters. For both benchmark calibrations of the model, the multipliers are quite small. And they actually rise 
a little as we move from the Bfixed calibration to the Bflex calibration. This small increase is mostly 13 due to the change in the properties of the stochastic process governing public spending across the two calibrations.

Table 5: Experiments (Perfect information)

\begin{tabular}{lccc}
\hline \hline Model & $\mu_{1}$ & $\mu_{4}$ & $\mu_{8}$ \\
\hline (1) Benchmark Fixed & 0.0315 & 0.0508 & 0.0621 \\
(5) Benchmark Flexible & 0.1044 & 0.0836 & 0.0781 \\
\hline \hline
\end{tabular}

Figure 1: IRF to a Fiscal Shock - Perfect Information
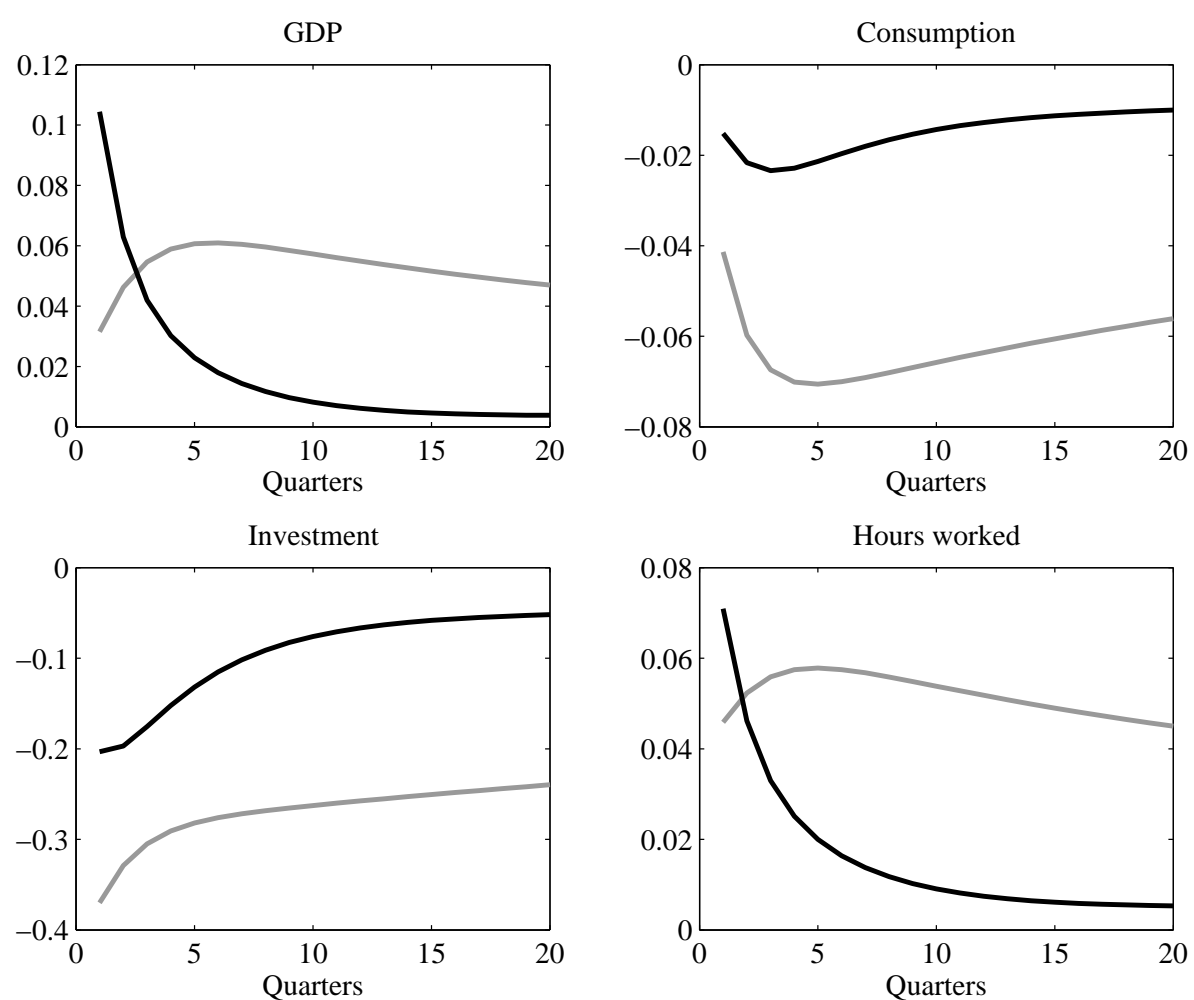

Note: dark line: Benchmark flexible (Post-1980), Gray line: Benchmark fixed (Pre-1980)

Figure 1 shows why we are getting these counterfactual results. The impulse response functions for consumption and investment fall under either calibration. And hours worked rise. This is a familiar result from the RBC literature. Households see the increase in government spending as tax liability that decreases their permanent income: they respond by working more, consuming less and investing less. In a sticky price setting the output multipliers are very small. Something

\footnotetext{
${ }^{13}$ Another reason, which will play an important role under imperfect information, has to do with the conduct of monetary policy. With the parametrization used, under passive policy (e.g. a constant money growth rule), a positive fiscal shock would increase inflation and depreciate the domestic currency. Under either a peg or a flexible exchange rate regime with a Taylor rule, monetary policy must become contractionary, and this subdues the fiscal multiplier. It turns out that policy is somewhat more contractionary under the peg.
} 
must be done in order to counter this wealth effect on aggregate demand if the model is to explain the empirical observations.

As explained above, we have chosen to do this by adding imperfect information. From now on, we assume that households and firms have to base their decisions on imperfect signals about the macroeconomic shocks.

\subsection{Imperfect information: Output multipliers in the benchmark calibrations}

The first and last lines of Table 6 report the cumulative output multipliers for our two benchmark calibrations. In the Bfixed calibration, the first quarter multiplier is greater than one, and then the multipliers tapers off at the four and eight quarter horizons. In the Bflex calibration, the multipliers are dramatically smaller at all horizons. These model generated multipliers capture quite well the patterns reported in the empirical literature, and in particular, their significant decline over time 14 .

Figure 2 shows IRFs from the two benchmark calibrations. With imperfect information, consumption and investment respond positively to an unanticipated increase in government spending. And this increase in aggregate demand is much more pronounced in the Bfixed calibration, explaining the much larger response of GDP in the case of fixed rates.

Why do consumption and investment rise when we add imperfect information? The answer lies in Figure 3, which shows how households' perceptions of the paths of the underlying shocks are affected by an unanticipated increase in government spending. Households do not know exactly what kind of shocks have occurred. The perceptions they form from observing noisy signals (but recall that they observe the nominal interest rate and the exchange rate without error) are such that they assign probabilities to an increase in government spending, to an improvement in technology, to an increase in world inflation, and to an increase in foreign preference for the domestic good having taken place. The first possibility would lower permanent income (by increasing tax liabilities), but all of the other possibilities would increase their permanent income. In equilibrium, confusion about the source of the shock causes the perceived wealth effect to be positive, and households increase their consumption and investment 15

A noteworthy feature is that, under flexible exchange rates, the multiplier does not appear to be sensitive to the existence or absence of imperfect information (compare the second line of Table 5 with the last line of table 6). While it is quite sensitive under a fixed regime (compare

\footnotetext{
${ }^{14}$ Interestingly, the number for the 4-quarter Canadian multiplier in pre-1980, 0.7, is almost identical to the corresponding number reported by Perotti, 2005, (0.6).

15 As noted earlier, adding rule of thumb consumers is the more popular way of making the consumption response positive. However, that approach has problems with the response of real wages, which Fatas and Mihov (2003) find to be positive in the data. Our model predicts a positive response of real wages.
} 
Figure 2: IRF to a Fiscal Shock - Imperfect Information
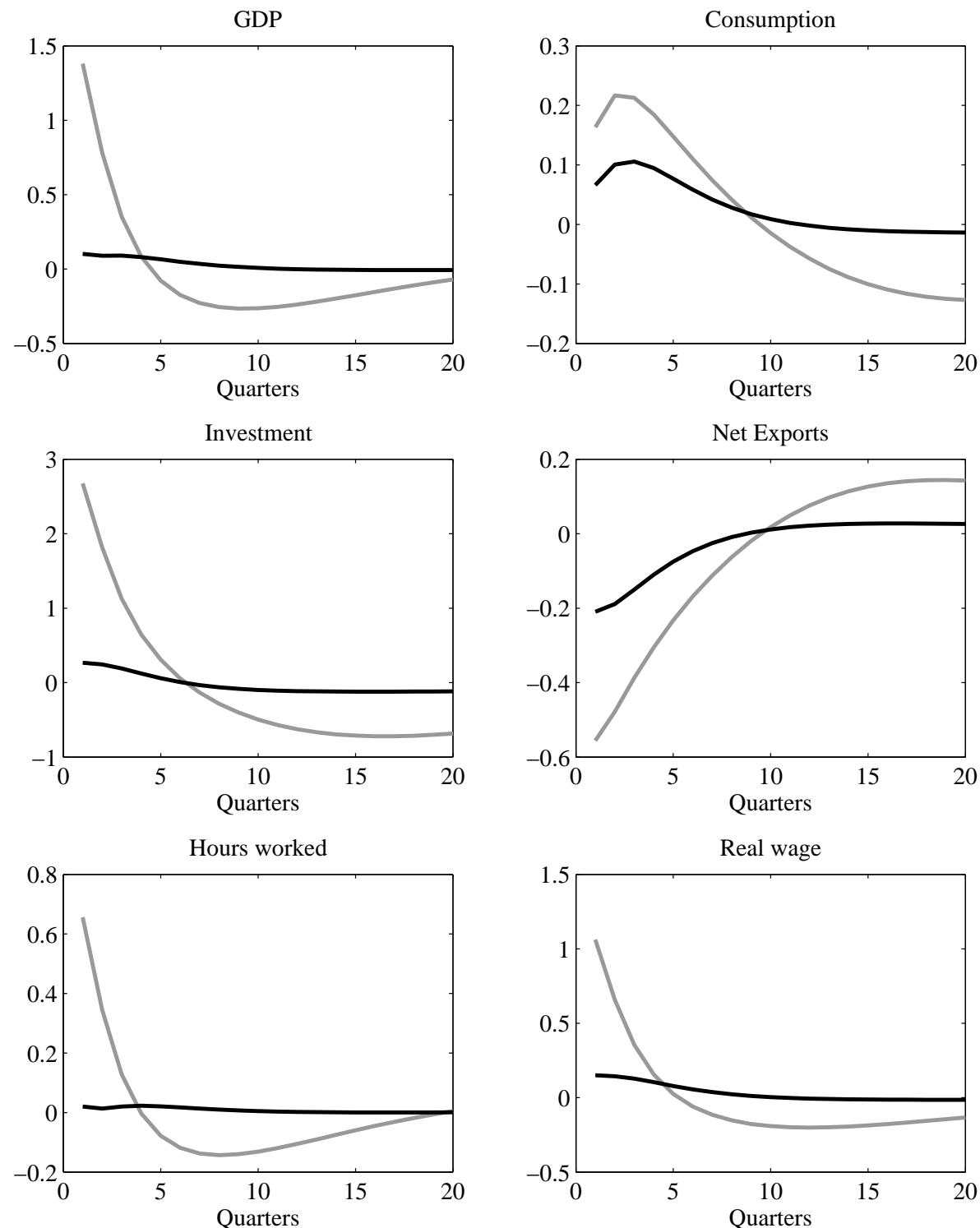

Note: dark line: Benchmark flexible (Post-1980), Gray line: Benchmark fixed (Pre-1980) 
Figure 3: Perceived Shocks Following a Fiscal Shock (Imperfect Information)
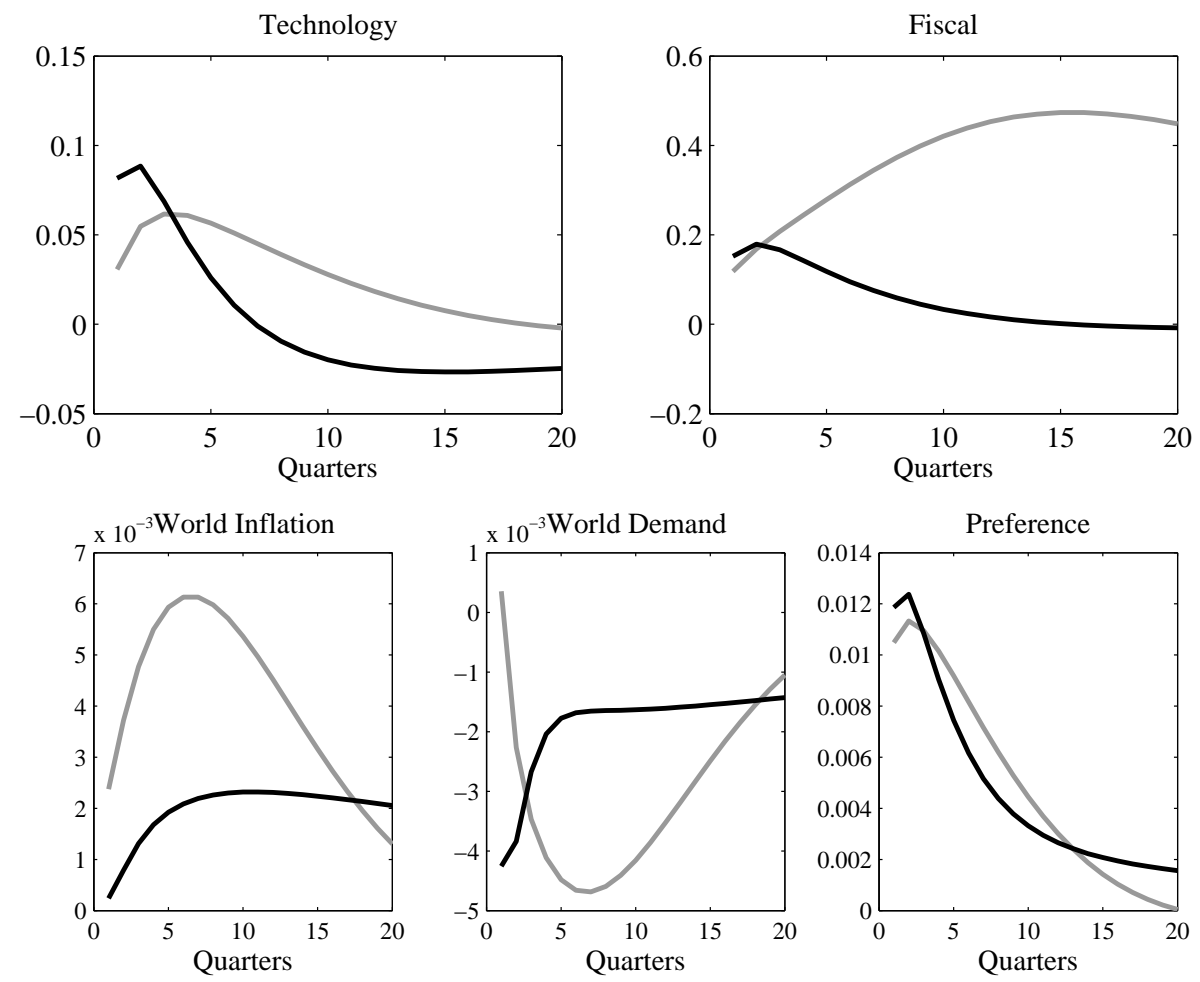

Note: dark line: Benchmark flexible (Post-1980), Gray line: Benchmark fixed (Pre-1980) 
the first line of Table 5 to the first line of table 66. In order to shed some light on this result it is instructive to solve the model under a flexible exchange rate regime and passive monetary policy (e.g. a constant money growth rule, a standard feature of the Mundell-Fleming model) as this can also help distinguish between the effects of the exchange rate regime per se from that those of the domestic monetary procedure in place. Under perfect information, following a positive fiscal shock the nominal interest rate increases. Inflation increases by more and the real interest rate declines. The domestic currency experiences a nominal (0.08) and real depreciation. Consequently, under either a peg or a flexible exchange rate regime with a Taylor rule the monetary policy reaction must involve tightening. The -already small- multiplier declines and becomes comparably small across the two regimes. The picture is completely different under imperfect information. In this case, the multiplier is virtually zero under the M-rule. There is a reduction in inflation - relative to the steady state - $(-0.15)$ an increase in the real interest rate and a large nominal (and real) appreciation of the domestic currency (-0.65). Under a peg, monetary policy must become very expansionary (the real interest rates declines significantly) in order to avert the large currency appreciation. It is the size of the monetary expansion that is behind the large multiplier. Under a flexible exchange rate regime, on the other hand, the reduction in inflation triggers a reduction in the real interest rate too, which acts to increase output. But because the expansion is limited (the decrease in inflation is modest), and more importantly, the monetary reaction to price developments is rather weak (recall that $\kappa_{\pi}=1.3$ ) the monetary expansion is modest ${ }^{16}$, which limits the size of the increase in the multiplier relative to both the M-rule and the peg. Note, though, that the fiscal multiplier would be much higher if the monetary authorities were strict inflation targeter ${ }^{17}$, see section 2.5 .

\subsection{Luck, a change in monetary policy, or globalization?}

What are the factors that account for the rather dramatic fall in government spending multipliers? There are three candidates in our modelling. The first is luck: in the Bflex calibration, the stochastic process for government spending is less volatile. The second is monetary policy: in the Bflex calibration, the fixed rate regime yields to an estimated interest rate rule that places very little weight on exchange rate stabilization. And the third is globalization: in the Bflex calibration, capital controls (modeled as a cost of holding foreign assets) are relaxed, and the economy is more open to trade.

In Table 6, we consider these factors one at a time. In the second line, we have replaced the

\footnotetext{
${ }^{16}$ The decline of the real interest rate is -0.12 and -0.01 under a peg and a flexible with an interest rate rule respectively.

${ }^{17}$ Strict inflation target, say $\kappa_{\pi}=\infty, \kappa_{y}=0$ would make the multiplier increase by an order of four! Nevertheless, the multiplier would still remain smaller under a flexible regime because the size of the decrease in inflation is small relative to that in the exchange rate.
} 
Table 6: Experiments (Individual Effects)

\begin{tabular}{lccc}
\hline \hline Model & $\mu_{1}$ & $\mu_{4}$ & $\mu_{8}$ \\
\hline (1) Benchmark Fixed & 1.3804 & 0.6899 & 0.2674 \\
(2) Flexible Exchange Rate & 0.1620 & 0.1434 & 0.1238 \\
(3) Lower Capital Controls $(\chi=0.0025)$ & 1.1066 & 0.5901 & 0.2862 \\
(4) Higher Imports $(\omega=0.72)$ & 0.5837 & 0.2992 & 0.1258 \\
(5) New Fiscal Shock $\left(\rho_{g}=0.78, \sigma_{g}=0.0154\right)$ & 1.5409 & 0.7854 & 0.2698 \\
$(6)$ Benchmark Flexible & 0.1015 & 0.1265 & 0.1364 \\
\hline \hline
\end{tabular}

fixed exchange rate regime with the estimated Taylor rule, but we have held all of the other parameters in the Bfixed calibration unchanged. In the third line, we have relaxed the capital controls, but we held all the other parameters unchanged. In the third and fourth lines, we similarly consider changes in openness and in the government spending process.

The change in monetary policy clearly makes the largest marginal contribution to the fall in government spending multipliers; for example, it brings the first quarter multiplier $95 \%$ of the way to the multiplier in the Bflex calibration. Openness is the next most important factor, in terms of its marginal contribution ( $62 \%$ of the way for the first quarter multiplier). Relaxing capital controls is a rather distant third (about 20\%). And luck actually increases the multipliers slightly: when the government spending process becomes more stable, households put more weight on the possibility of other shocks, and they increase their consumption more.

There is, however, a major caveat here: the marginal contributions in Table 6 may be misleading indicators of how important the various factors might be. These factors interact with each other when they are combined, as in the Bflex calibration. The marginal contributions are not orthogonal to each other, and the cumulative effects of adding one factor after another depend upon the order in which they were added.

Table 7: Experiments (Cumulative Effects)

\begin{tabular}{llll}
\hline \hline (1) Benchmark Fixed & 1.3804 & 0.6899 & 0.2674 \\
$(2)=(1)+$ Flexible Exchange Rate & 0.1620 & 0.1434 & 0.1238 \\
$(3)=(2)+$ Higher Imports $(\omega=0.72)$ & 0.0988 & 0.1046 & 0.1033 \\
$(4)=(3)+$ Lower Capital Control $(\chi=0.0025)$ & 0.0876 & 0.0988 & 0.1017 \\
(5) Benchmark Flexible & 0.1015 & 0.1265 & 0.1364 \\
(6) Benchmark Flexible (Money Growth Rule) & 0.0078 & 0.0406 & 0.0673 \\
(7) Benchmark Flexible, Stricter Inflation Targeting & 0.2899 & 0.1666 & 0.1056 \\
(8) Benchmark Flexible, Strict Inflation Targeting & 0.4010 & 0.1908 & 0.1066 \\
\hline \hline
\end{tabular}

Table 7 reports the cumulative marginal contributions that the factors make when they are added in a specific way. First, based on Table 6, we selected the factor with the largest individual 
marginal contribution; this is the change in monetary policy. We imposed this change, and then we considered each of the other factors, one at a time. We selected the factor that, once again, made the largest marginal contribution. This led us to select openness. We continued the process, selecting looser capital controls, and then the more stable fiscal process.

Looking at either Table 6 or Table 7 , the change in monetary policy is clearly the most important factor in the model's explanation of the evolution of government spending multipliers. One of the globalization factors - openness - also seems to be important. Easing capital controls is somewhat important, and luck seems quite unimportant.

\subsection{How flexible rates and openness reduce the government spending multi- pliers}

The IRFs in Figures 4 and 5 help explain the progression of multipliers in Table 7. In Figure 4. IRFs from the Bfixed calibration are compared to IRFs from a calibration in which the fixed exchange regime has been replaced by the estimated Taylor rule, and all other parameters are as in the Bfixed calibration; this corresponds to moving from line 1 to line 2 in Table 7 . In Figure 5. the second set of IRFs from Figure 4 are compared to IRFs from a calibration in which we have both the Taylor rule and increased openness; this corresponds to moving from line 2 to line 3 in Table 7 .

In Figure 4, the importance of exchange rate targeting is readily apparent: the response of GDP to an unanticipated increase in government spending is much greater in the fixed rate regime. The reason for this is also readily apparent. With flexible rates, the nominal exchange rate would appreciate. Monetary policy must be loosened to counter this in the fixed rate regime. Real interest rates fall further than they would with the Taylor rule, and this causes both consumption and investment demand to rise more. And, of course, the fact that the exchange rate does not appreciate means that more of the increase in consumption falls on the domestic good. 18

In Figure 5, the importance of openness is also apparent: the response of GDP is less when the import share is larger. When a larger import share of the increase in demand falls more on the foreign good, and aggregate demand for the domestic good rises less. With the Taylor rule, the appreciation in terms of trade is smaller and the fall in net exports is dampened.

\footnotetext{
${ }^{18}$ The terms of trade must appreciate with the Taylor rule for this "Mundell-Flemming" explanation to work. There is currently some debate about this in the empirical literature. Ravn, Schmitt-Grohe and Uribe (2007) and Monacelli and Perotti (2006) find that the real exchange rate depreciates. Canzoneri, Cumby and Diba (2003) and Chinn (1999) find that it appreciates, which is also the more conventional view.
} 
Figure 4: IRF to a Fiscal Shock - Imperfect Information (Taylor Rule)
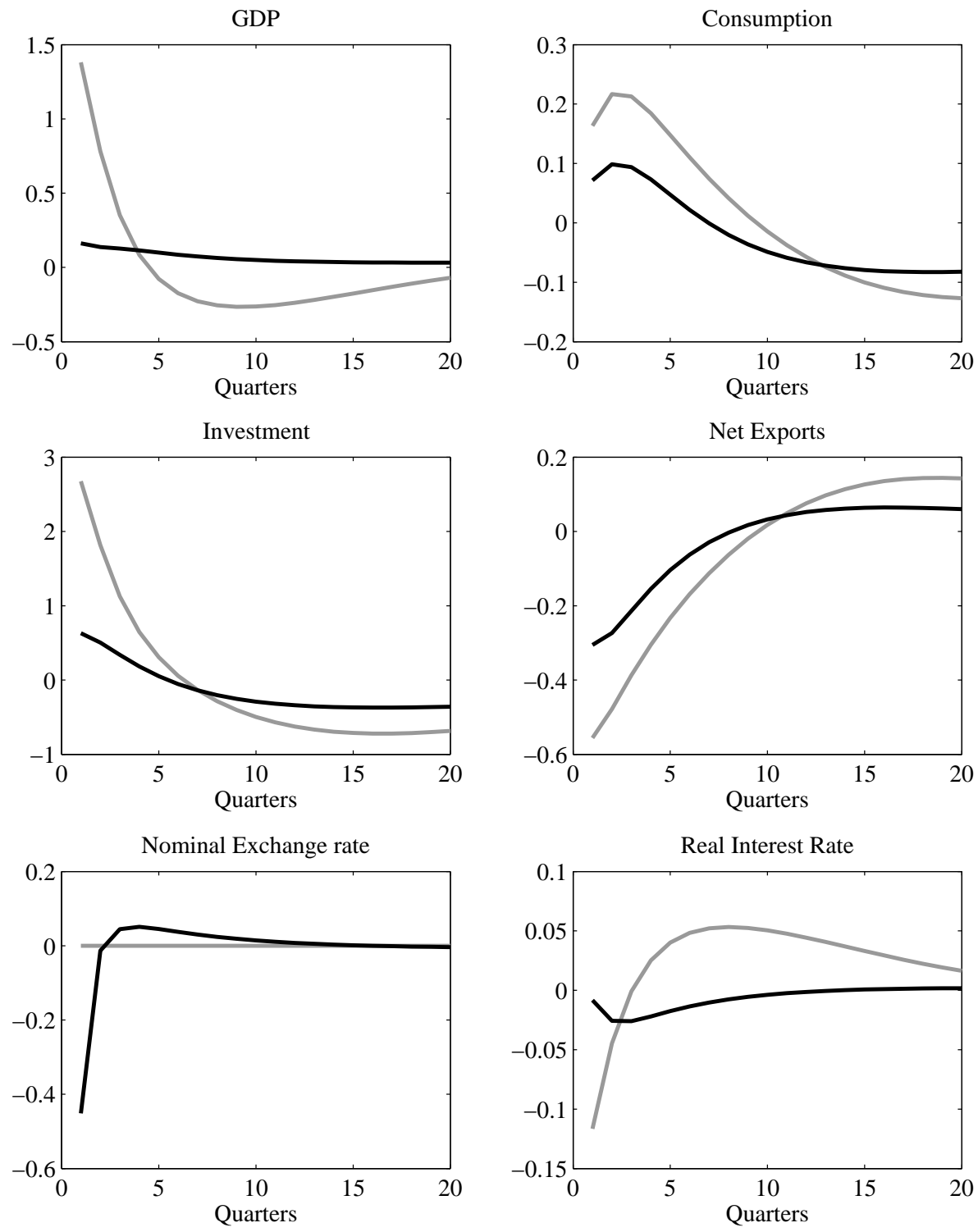

Note: dark line: Taylor rule, Gray line: Benchmark fixed (Pre-1980) 
Figure 5: IRF to a Fiscal Shock - Imperfect Information (Openness)
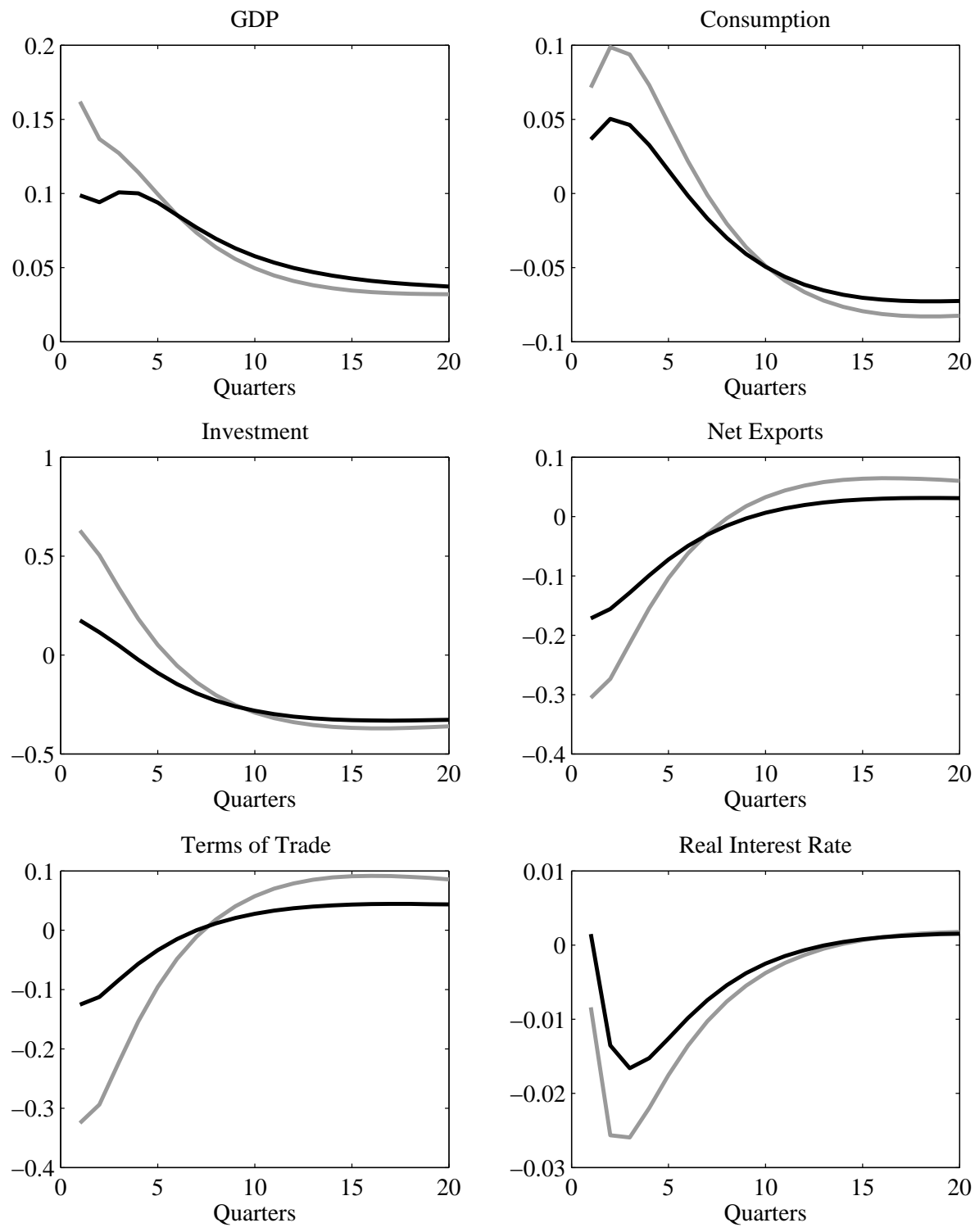

Note: dark line: Taylor rule+Greater openness, Gray line: Taylor rule 


\subsection{Money targeting and strict inflation targeting}

Since the change in monetary policy was shown to be the most important factor it the evolution of the model's multipliers, it may also be interesting to consider alternative specifications of monetary policy. Table 7 shows how the multipliers in the Bflex calibration would change if the estimated Taylor rule were replaced by a fixed money growth rule or stricter inflation targeting rules (where $\kappa_{\pi}=3$ and $\kappa_{y}=0$ in row (7) and $\kappa_{\pi}=\infty$ and $\kappa_{y}=0$ in row (8)).

The money growth rule is interesting for conceptual reasons: it is the logical counter part to the fixed exchange rate regime in the "Mundell-Flemming" paradigm. The output multipliers are lower under the money growth rule than under the estimated Taylor rule or under the fixed exchange rate. This is due to the fact that the model generates a reduction in inflation and an appreciation in the nominal exchange rate under the money targeting rule. Under the Taylor rule, the monetary authorities react to the lower inflation by lowering interest rates, which stimulates the economy. Similarly loose policy must be followed under a peg in order to prevent the appreciation of the domestic currency.

The strict inflation targeting rule is interesting because it may be where central banks in the OECD countries are heading. As explained earlier, stricter inflation targeting gives a stronger response to the government spending shocks than does the Taylor rule. The stronger reaction of monetary policy to the reduction in inflation that would have been allowed to occur under passive money growth policy is behind this result.

\section{Conclusion}

We have shown that a New Keynesian model is capable of explaining the evolution of consumption responses and output multipliers that has been observed in the data. In our model, monetary policy's movement away from exchange rate stabilization, and to a standard Taylor Rule, was the most important factor in this explanation. However, globalization (in the form of increased openness, and to a lesser extent, the relaxation of capital controls) also played a role. Luck (in the form of a more stable government spending process) was not an important factor. We modeled imperfect information and learning to overcome the negative wealth effect that normally decreases consumption in response to an increase in government spending. Absent this imperfect information, our model could not explain the evolution of government spending multipliers. However, reversing the negative wealth effect also implies that investment rises, and there is scant empirical evidence to support this result. Disentangling the movements of consumption and investment in a New Keynesian model remains a puzzle in the New Keynesian paradigm. 


\section{References}

Boldrin, Michele, Lawrence Christiano, and Jonas Fisher, 1999, Habit Persistence, Asset Returns and the Business Cycle, American Economic Review, 91(1), 149-166.

Canzoneri, Matthew, Robert Cumby and Behzad Diba, 2003, New Views on the Transatlantic Transmission of Fiscal Policy and Macroeconomic Policy Coordination, in Marco Buti (ed.) Monetary and Fiscal Policies in EMU: Interactions and Coordination, Cambridge University Press.

Chinn, Menzie, 1999, Productivity, Government Spending and Real Exchange Rates: Empirical Evidence for OECD Countries in Ronald McDonald and Jerome Stein, ed, Equilibrium Exchange Rates, Kluwer Academic Publishers, Boston, pg. 163-190.

Christiano, Lawrence, Martin Eichenbaum, and Charles Evans, 2005, Nominal Rigidities and the Dynamic Effects of a Shock to Monetary Policy, Journal of Political Economy 13(1), 1-45.

Coenen, Gunter and Roland Straub, 2005, Does Government Spending Crowd in Private Consumption: Theory and Empirical Evidence for the Euro Area, International Finance, 8(3), 435-470.

Collard, Fabrice and Harris Dellas, 2006, Monetary Misperceptions, Output and Inflation Dynamics, mimeo.

Dib, A., 2003, Monetary Policy in Estimated Models of Small Open and Closed Economies, Bank of Canada, WP 2003-27.

Erceg, Christopher, Luca Guerrieri and Christopher Gust, 2005, SIGMA, A New Open Economy Model for Policy Analysis, Federal Reserve Board, International Finance Discussion Paper \# 835 .

Fatas, Antonio and Ilian Mihov, 2003, The effects of fiscal policy on consumption and employment: Theory and Evidence, mimeo, INSEAD.

Galí, Jordi, David López-Salido and Javier Valles, 2007, Understanding the Effects of Government Spending on Consumption, Journal of the European Economic Association, 5(1), 227-270. Lubik, Thomas. and Frank Schorfheide, 2007, Do central banks respond to exchange rate movements? A structural investigation, Journal of Monetary Economics, 54, 1069-1087.

Mihov, Ilian, 2003, Discussion of "Understanding the Effects of Government Spending on Consumption” by Jordi Galí, David López-Salido and Javier Valles, INSEAD mimeo.

Monacelli, Tommaso, and Roberto Perotti, 2006, Fiscal Policy, the Trade Balance and the Real 
Exchange Rate: Implications for International Risk Sharing, Mimeo.

Perotti, Roberto, Estimating the Effects of Fiscal Policy in OECD Countries, 2004, mimeo.

Ramey, Valerie and Matthew Shapiro, 1998, Costly Capital Reallocation and the effects of Government Spending, Carnegie Rochester Conference on Public Policy, pp. 145-194.

Ravn, Morten, Stephanie Schmitt-Grohe, and Martin Uribe, 2007, Explaining the Effects of Government Spending Shocks on Consumption and the Real Exchange Rate, mimeo.

Svensson, Lars and Michael, Woodford, 2003, Indicator Variables for Optimal Policy, Journal of Monetary Economics, 50(3), 691-720. 


\section{A The first order conditions of household's program}

$$
\begin{aligned}
c_{t}: & \frac{1}{c_{t}-b c_{t-1}}-\beta b \mathbb{E}_{t}\left[\frac{1}{c_{t+1}-b c_{t}}\right]=\Lambda_{t} P_{t} \\
h_{t}: & \nu_{h} h_{t}^{\sigma h}=\Lambda_{t} P_{t} w_{t} \\
u_{t}: & r_{k, t}=z^{\prime}\left(u_{t}\right) \\
M_{t}: & \nu_{m}\left(\frac{M_{t}}{P_{t}}\right)^{-\sigma_{m}}=\Lambda_{t} P_{t} \frac{R_{t}-1}{R_{t}} \\
i_{t}: & \Lambda_{t} P_{t}=q_{t}\left(1-\varphi\left(\frac{i_{t}}{k_{t}}-\delta\right)\right) \\
B_{t}^{\mathrm{D}}: & \Lambda_{t}=\beta R_{t} \mathbb{E}_{t} \Lambda_{t+1} \\
B_{t}^{\mathrm{F}}: & \Lambda_{t}\left(1+\chi\left(\frac{e_{t} B_{t}^{\mathrm{F}}}{P_{t}}\right)\right)=\beta R_{t}^{\star} \mathbb{E}_{t} \frac{e_{t+1}}{e_{t}} \Lambda_{t+1} \\
k_{t+1}: & q_{t}=\beta \mathbb{E}_{t}\left[\Lambda_{t+1} P_{t+1} r_{k, t+1}+q_{t+1}\left(1-\delta+\frac{\varphi}{2}\left(\left(\frac{i_{t+1}}{k_{t+1}}\right)^{2}-\sigma^{2}\right)\right)\right]
\end{aligned}
$$

where $\Lambda_{t}$ and $q_{t}$ denote the Lagrange multiplier to, respectively, (14) and (15). 